\title{
Earth construction in Algeria between tradition and modernity
}

1 Bousmaha Baiche DipArch, MPhil, PhD Research Fellow, School of Architecture, Faculty of Technology, Design and Environment, Oxford Brookes University, Oxford, UK

2 Mohamed Osmani Dip Arch, MPhil

Senior Lecturer, Department of Civil and Building Engineering, Loughborough University, Loughborough, Leicestershire, UK
3 Nicholas Walliman Dip Arch, PhD Senior Lecturer, School of Architecture, Faculty of Technology, Design and Environment, Oxford Brookes University, Oxford, UK

4 Raymond Ogden BA(Hons), Dip Arch(1st), PhD Professor, School of Architecture, Faculty of Technology, Design and Environment, Oxford Brookes University, Oxford, UK
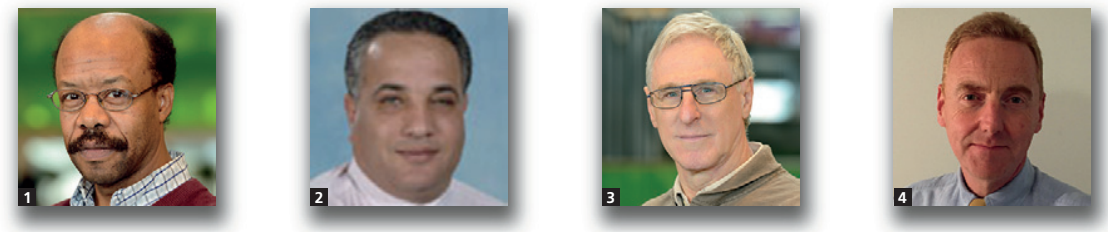

In the south of Algeria, many indigenous settlements have been built using local earth construction techniques; in the north, despite the availability of suitable earth, only a few rural contemporary settlements have been built using 'improved' earth construction. This paper adopts a case study approach to examine and compare structural deficiencies of two earth-built housing settlements in different regions in Algeria. In the indigenous earth settlement in the south, where adobe was used in combination with local timber and stones, the dwellings exhibit many structural defects. Stabilisation of the soil and introduction of modern materials in the contemporary rammed earth settlement in the north has not, however, helped produce structurally adequate dwellings. These dwellings also exhibited many cracks and debonding of rendering, and thus did not fulfil the requirements and aspirations of their occupants. The study concludes that for a potentially successful earth building scheme there are inter-related factors that should be considered: selection of an appropriate soil and construction technique, implementation of a suitable structural design, construction and post-completion processes, availability of relevant skills and provision of adequate training on the construction technique.

\section{Introduction}

The choice of building materials, after taking into account the social and economic context of a society, is probably one of the most challenging aspects of planning of human settlements. In many developing countries, since their independence, there has been an increasing and often inappropriate adoption of western construction materials and techniques (Agarwal, 1982; Hadjri et al., 2007). Yet, in these countries, there are many examples of vernacular buildings that reflect the use of locally available materials, appropriate indigenous construction techniques and adequate means for the execution of the construction process. In some of these countries, these indigenous building techniques have proved, over many centuries, to be an appropriate way to bring decent dwelling standards to the rural or semi-rural population (Hadjri, 2005; Kuban, 1982). It is argued that dwellings built with local materials provide several benefits to their occupants in comparison with those built with imported materials and relying on modern technology. The occupants can not only build but also maintain their dwellings and modify these to meet whatever changing circumstances life may produce (Arrecchi, 1984; Norton, 1997).

For many centuries, unbaked earth has been used in every continent as a building material not only for housing, but also for the construction of vast, prestigious monuments (BADC, 1985; CRATerre, 1985; Duly, 1979; Eaton, 1981, 1982; Jenner, 1984; McHenry, 1984). At least 20 different traditions of earth construction are known, but 'pisé' or rammed earth and adobe predominate (Clough, 1947; Eaton, 1982; Fodde, 2009; Keefe, 2005; Spence and Cook, 1983; Swenarton, 2003; Walker, 
2005). Earth as a building material tends to be used for wall construction and each area has its own processes, not only for producing the necessary building material but also for construction processes using the material. Each earth construction technique is characterised by its advantages and disadvantages (CRATerre, 1985; Germen, 1979; Guillaud, 1985; Jeannet et al., 1986).

Over the last century, in the 'developed' world, earth construction has undergone a steady decline; however despite this, it has been used in some cases. Many developing countries have continued to use earth as a building material as it was once indigenously used, particularly in poor, rural areas with a rapidly increasing population (CRATerre, 2005). In other developing countries, particularly those enriched by the oil boom, earth construction has declined and has been replaced by western building materials and techniques (Agarwal, 1982; Eaton, 1981).

There has been a considerable revival of interest in earth architecture in the latter developing countries. Some have been carrying out research in the field of intermediate earth technology for many years (Adam and Agib, 2001; CIDRLD, 2004; Olotuah, 2002). Others adopted western building materials and techniques on a large scale, but the scarcity and increasing prices of these materials has led to more recent consideration of the potential to use readily available earth - a new perspective encouraged by the increasing awareness at political, intellectual, architectural and cultural levels. This interest has been reflected in international exhibitions and symposia promoting the use of local building materials, particularly earth (CIB and Rilem, 1983; Courtney, 1986; Fathy, 1970, 1973; Jiménez Delgado and Ignacio Cañas Guerrero, 2006; Mulligan, 1987; Nyerere, 1977; Schleifer, 1984; Schumacher, 1973; Swan, 1980).

The wide availability of earth and its reusability are seen as a major advantage, and its use is cost effective compared with manufactured building materials. It is versatile and so can be used to reflect cultural and architectural diversity, and offers a means of providing comfortable, easily extended or altered housing for all strata of society (BADC, 1985; Beazley and Haverson, 1982; Emmot, 1981; Hall et al., 2012; Kateregga, 1983; Venkatarama Reddy and Jagadish, 2003).

Protagonists of earth as a building material value its ability to store energy and stabilise temperature, the so-called 'thermal mass' effect. In addition to energy savings at the production stage, unbaked earth buildings also require less heating and cooling, as the earth walls ensure a substantial reduction in heat loss and a general feeling of what is called 'thermal comfort' (Agarwal, 1981; Chel and Tiwar, 2009; Evans, 1980; Fathy, 1986; Hyland, 1984; Morton et al., 2005; Parra-Saldivar and Batty, 2006; Shukla et al., 2009).
However, earth material used indigenously has drawbacks, mainly due to its mechanical and physical properties (Doat et al., 1979; Yorulmaz, 1982). Nevertheless, these drawbacks can be minimised by use of an appropriate design and improvement in the intrinsic qualities of earth, particularly strength and durability, through stabilisation that is achieved by the addition of a binder; for example, a small amount of cement and/or lime, and/or the compression of the particles that constitute the material by using a press machine to produce strong compressed earth blocks. It should be noted that these conventional binders, that is cement and lime, have been a subject of concern due to their association with adverse effects on the environment - carbon dioxide emissions, energy intensive manufacture, significant depletion of raw material resources and unsightly quarrying and so on. There are now attempts to minimise the use of these materials by enhanced use of alternative, complimentary and/or supplementary natural, industrial or agricultural waste/by-product materials (Angulo-Ibáñez et al., 2012; Houben and Guillaud, 1994; Ngowi, 1997; Pacheco-Torgal and Jalali, 2012).

Compressed earth blocks are the modern version of the unbaked moulded bricks and use earth with similar characteristics to those of pisé (rammed earth), but with higher clay content (up to $25 \%$ ), less gravel and always more sand. The slightly wet soil is compacted in presses of diverse types that vary widely in efficiency (Ciancio and Boulter, 2012; CRATerre, 1985; Guillaud, 1985; Houben et al., 1996; Jayasinghe and Kamaladasa, 2007; Montgomery, 2002).

Stabilised compressed earth blocks have the following advantages over pisé (rammed earth)

- the possibility of spreading out brick making over a period

- the reduction of cracks in walls as shrinkage occurs predominantly during drying

- greater flexibility in use

- possibility of off-site production of the soil material.

In addition, stabilised compressed earth blocks present the following advantages over unbaked moulded bricks

nossibility of immediate storage

- relatively small making and drying area (which may be covered) needed

a more regular shape of brick

- possibility of making special forms of the blocks - for example, hollow blocks with bell and spigot joint, and tiles

- possibility of stabilising only the surface of the block

- higher resistance to compression

- better finish (Ferm, 1985; Keable, 1996; McHenry, 1989; Millogo et al., 2008; Minke, 2000; Nowamooz and Chazallon, 2011; Prin and Cubaid, 1983). 
In Algeria, vernacular earth dwellings have been built for many centuries in different parts of the country, especially in the hot, arid zones. These dwellings have exhibited many structural deficiencies. In addition, few experimentally improved earth settlements, using stabilised earth, were built in the 1970s.

The main aim of this paper is to investigate if, and to what extent, the contemporary houses built with improved earth material displayed the deficiencies in strength and durability demonstrated in the old earth buildings in Algeria. Potential factors contributing to the defects are highlighted.

\section{Research design}

Two case studies were used (Figure 1). The first was aimed at identifying deficiencies in vernacular hand-made adobe block buildings, as per the literature. The second evaluated a contemporary settlement built with cement-stabilised soil rammed between metal frameworks, using pneumatic hammers, to firstly investigate the extent to which deficiencies in strength and durability identified in the old vernacular earth settlement occurred in the contemporary earth scheme, and secondly to identify and discuss potential contributing factors.

The first case study was Taghit, a village located in the southwest of Algeria. An empirical investigation was undertaken on the vernacular earth settlement where soil was used in

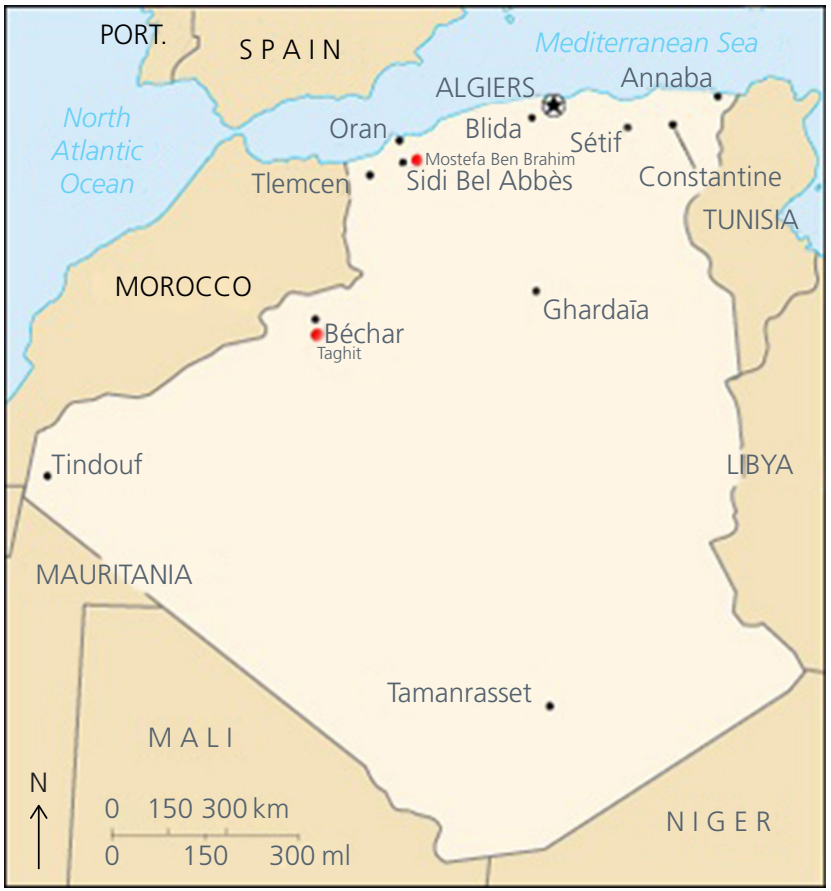

Figure 1. Location of Taghit, Sidi Bel-Abbes and Mostefa Ben Brahim on the map of Algeria combination with other local materials, including timber and stones. About 25 dwellings were surveyed and recorded by using checklists, sketch plan measurements, detailed recording of the construction elements and photographs. The investigation was necessary to identify characteristics (advantages and disadvantages) of local materials used, particularly earth, in order to assess the extent to which these were similar to those found in the literature and to ascertain any problems that were particular to this vernacular settlement. The case study included semi-structured interviews with local people living in vernacular dwellings and craftsmen in order to explore their perceptions of earth construction (Baiche, 1987).

The second case study was Mostefa Ben Brahim, a village located on the high plains, near the town of Sidi-Bel-Abbes. Twenty two stabilised rammed earth dwellings were surveyed. The standard layout of the dwellings is illustrated in Figure 2. The survey included a general empirical observation of the stabilised rammed earth housing scheme to identify any major alterations undertaken by the residents, and any visible patterns of structural and construction deficiencies. Detailed investigation was carried out on each dwelling of the housing sample using detailed checklists, recording sheets and photographs (Baiche, 1992).

The survey method used to detect defects in the houses in both case studies was influenced by the approach discussed by Staveley and Glover (1983). Structured interviews were carried out with the inhabitants of the housing sample to establish their perceptions of living in these dwellings, and with local authority officials (using semi-structured interview schedules) to identify their different levels of involvement in the building implementation and management of the housing scheme.

\section{Research findings}

\subsection{Introduction}

In both the vernacular earth settlement in Taghit and the stabilised rammed earth housing in Mostefa Ben Brahim, earth material has predominantly been used as a wall material. This paper focuses on the potential structural deficiencies in the walls of dwellings in both schemes. A comparative approach is adopted to discuss findings from both case studies.

\subsection{Findings}

The survey of the dwellings in both case study areas determined several structural deficiencies identified through cracks and render debonding. Several factors appeared to need careful consideration to potentially mitigate these structural deficiencies. These factors include

workmanship

- selection of earth to be used as a building material 

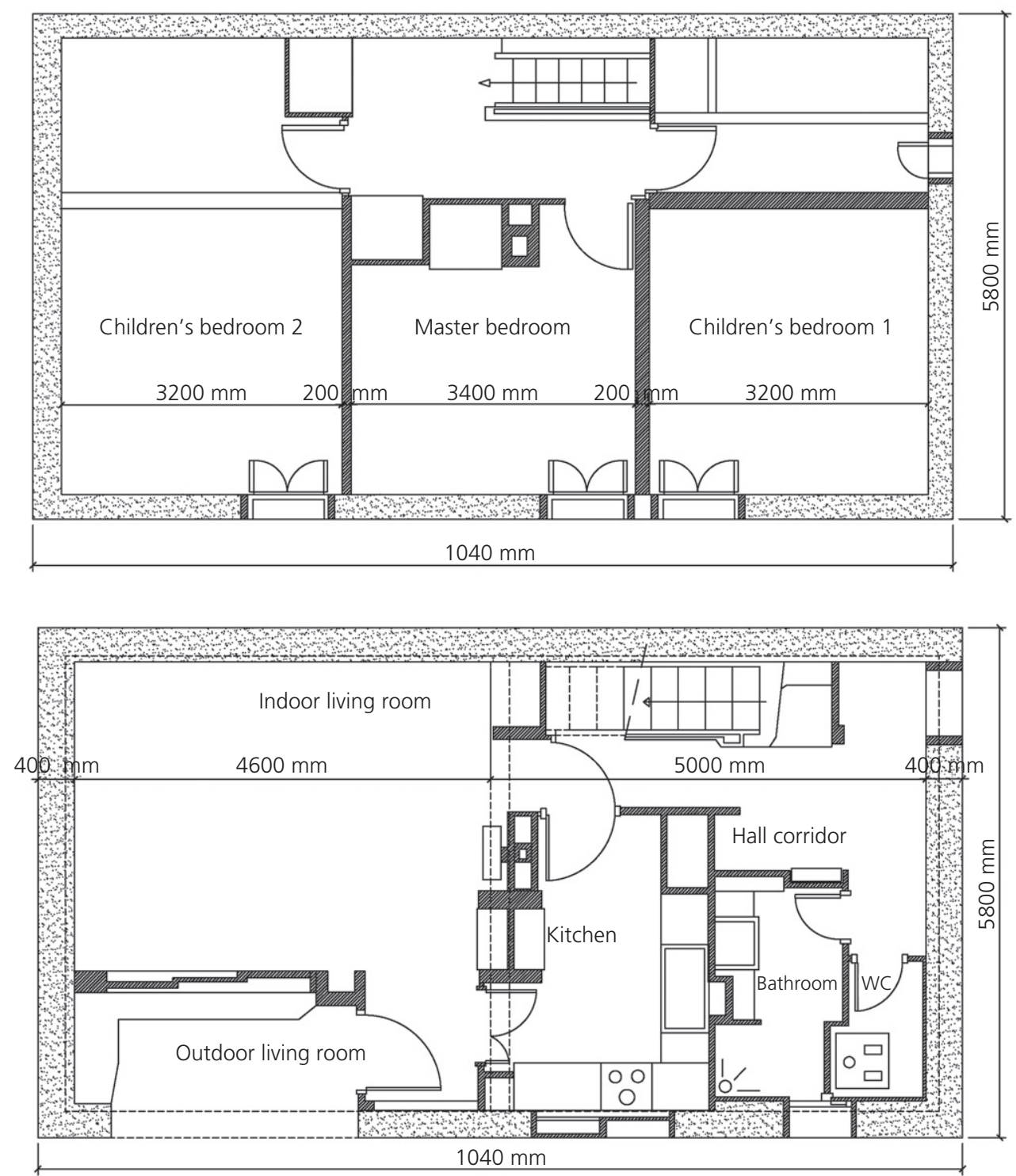

Figure 2. Standard plans of the stabilised rammed earth houses in the village of Mostefa Ben Brahim

design and construction of plinth wall

- interface between walls and plinth wall

- selection of frames for openings

- design and use of shutterings

- selection and design of render mix

rainwater evacuation system.

The findings from the survey are discussed under the following headings: selection of earth material, foundations and plinth walls, external walls, wall renders, door and window openings.

\subsubsection{Selection of earth material}

Traditionally, the earth used for constructing the dwellings in the Ksar of Taghit was usually obtained from the local river bed. It was first dug up using traditional tools and then mixed with a traditional stabiliser such as straw, wood shavings or animal dung; this mixture was then left to ferment for a certain period, sometimes until a strong odour emanated from it. According to the interviewed local builders, the river bed soil was not workable on its own; therefore, it was necessary to add a proportion of sand that is widely available locally. The average volumes used were approximately two or three volumes 
of sand and one volume of soil. This operation protected the bricks from considerable shrinkage and cracking, and improved their resistance and durability.

A sieve analysis was carried out on a soil sample retrieved from the same river bed. The results were as follows: $2 \cdot 96 \%$ retained on $2000 \mu \mathrm{m}$ sieve size, $2 \cdot 15 \%$ retained on $600 \mu \mathrm{m}$ sieve size, $21.49 \%$ retained on $200 \mu \mathrm{m}$ sieve size, $30.66 \%$ retained on $75 \mu \mathrm{m}$ sieve size and $42.47 \%$ passed through $75 \mu \mathrm{m}$ sieve size. In order to assess the suitability of the river bed soil for stabilisation, additional tests were carried out. The results were: addition of $\mathrm{Al}_{2} \mathrm{O}_{3}+\mathrm{SiO}_{2}+\mathrm{Fe}_{2} \mathrm{O}_{3}$ (aluminium oxide + silicon dioxide + iron oxide) to be greater than $75 \%$, river bed soil: $78.22 \%$; the loss on ignition to be less than $12 \%$, river bed soil: 9.67\%; soluble salt content $\left(\mathrm{K}_{2} \mathrm{O}+\mathrm{Na}_{2} \mathrm{O}\right)$ (potassium oxide + sodium oxide) to be less than $2 \%$, river bed soil: $2 \cdot 22 \%$; combined clay and silt fraction to be greater than $10 \%$, river bed soil: $42 \cdot 74 \%$. It was concluded that all the findings were positive with the exception of the soluble salts content of the river bed soil. This borderline excess could possibly affect the long-term durability of blocks made out of the river bed soil. However, as the river bed is unlikely to be used, this is not relevant for future building projects using stabilised earth.

A soil sample was retrieved from the quarry that provided the raw material for the earth dwellings in the village of Mostefa Ben Brahim. Using the standard method of wet sieving, the particle size distribution test of the soil sample indicated that $69 \cdot 01 \%$ of the soil was silt size or smaller - that is, $0.06 \mathrm{~mm}$. In fact, more than $35 \%$ of the soil was finer than $0.06 \mathrm{~mm}$. Therefore, it was concluded that the soil was fine soil - that is, silt or clay. Precisely, it was red silty clay with some flint gravel. A detailed particle size distribution analysis, using the pipette method, was carried out on $69.01 \%$ of the soil that passed through the $63 \mu \mathrm{m}$ BS test sieve. The sedimentation procedure produced the following results: $10 \cdot 11 \%$ of the soil was coarse silt $(0.06-0.02 \mathrm{~mm}), 11.50 \%$ of the soil was medium silt $(0.02$ $0.006 \mathrm{~mm}), 10 \cdot 70 \%$ of the soil was fine silt $(0.006-0.002 \mathrm{~mm})$ and $36.7 \%$ of the soil was clay $(<0.002 \mathrm{~mm})$. On the other hand, using the subsidiary method of dry sieving, the results of the particle size distribution of the soil sample retrieved from Mostefa Ben Brahim indicated that $19 \cdot 62 \%$ of the soil was silt size or smaller - that is $0.06 \mathrm{~mm} ; 97.89 \%$ of the soil was sand size or smaller - that is $2.00 \mathrm{~mm}$; and $97.37 \%$ of the coarse material was of sand size. According to this method, the Mostefa Ben Brahim soil was poorly graded silty or clayey sand.

To prepare the soil for building the stabilised earth houses in Mostefa Ben Brahim, CRATerre claimed to have corrected the particle size distribution of the soil with the addition of $50 \%$ sand obtained by crushing gravel. Therefore, the soil:sand ratio was 1:1. According to their records, the correction of the soil size particle distribution by adding $50 \%$ sand produced a particle size distribution curve that not only almost merged with the ideal curve of the appropriate soil for stabilised soil construction, but was also located within both the grading range limits for rammed earth and compressed bricks. While this limit of grading ranges guarantees a certain level of construction material efficiency, this does not mean that outside the limits of these grading ranges it is impossible to build with earth. It may be possible, but there may be some issues that need to be resolved, such as the long durability of the material used.

\subsubsection{Foundations and plinth walls}

In Taghit, the vernacular houses of the Ksar do not have conventional foundations. The entire Ksar stands on an immense rocky site (Figure 3); the bases of the walls and columns, erected directly on the rocky site, were reinforced with stones to make the plinth walls. The stones were joined with earth mortar, but due to poor workmanship, and the low resistance and durability of the earth-based joint mortar, much of the latter has been eroded and washed away, making the stones protrude. As a result, the resistance within the bases of the walls and columns is compromised.

In the village of Mostefa Ben Brahim, foundations of the sample of 30 houses built with stabilised rammed earth consist of a wide continuous footing made of reinforced concrete to transmit effectively the heavy weight of the rammed earth construction to the firm ground. The foundations were raised above the ground using a plinth wall made of water-proof lean concrete to prevent any possible water rise from the natural ground or any water coming into the house from outside.

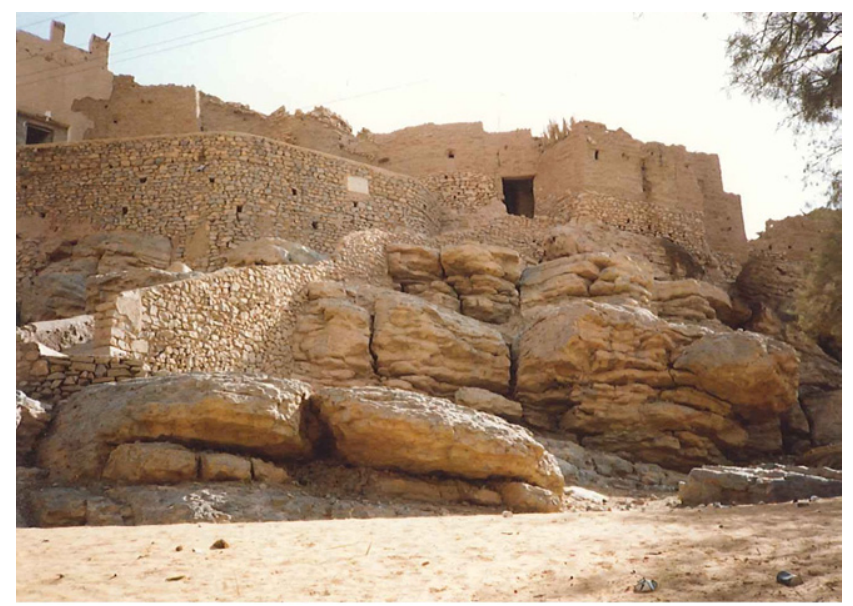

Figure 3. Rocky site on which the Ksar of Taghit was built. Bottom part of walls built with stones joined with earth-based mortar 
The external walls and the plinth wall of the ground floor have the same thickness - that is, $40 \mathrm{~cm}$ - to prevent any potential erosion of the base of the walls in contact with the plinth wall.

Despite all the recommendations and the precautions considered during the construction of the foundations and plinth walls of the stabilised rammed earth-built houses, structural problems were observed in many plinth walls of the surveyed houses. The main problem identified consists of cracks running across the plinth walls.

Cracks in the plinth walls had adverse implications, especially in the case of a party wall shared by adjoining properties. On several occasions, a resident has pointed out that water had infiltrated into their living room from the courtyard of their neighbour's house through the cracks in the plinth wall, as the wall was exposed to the neighbour's courtyard.

\subsubsection{External walls}

Walls of the vernacular dwellings in the Ksar of Taghit were built with hand-made, loaf-like earth bricks with no standard dimensions. As a result, not only the thickness of the walls varied, but several walls were neither vertical nor straight. In addition, the poor workmanship of the local indigenous earth technique led to walls in many dwellings exhibiting a variety of cracks, some very severe at wall corners (Figures 4-6). Another problem was the poor grip between the earth material and the frames of the door and window openings that was aggravated by violent slamming of doors and windows. Several walls have been eroded by occasional rains and frequent violent winds and sandstorms.

Recommendations have been put forward to help prevent such defects from occurring in contemporary earth buildings. Nevertheless, similar defects were also observed at the stabilised rammed earth houses in Mostefa Ben Brahim, although the assumptions were that this housing scheme should have been constructed with respect to codes and standards (Figure 7). It should be noted that only the external shells (external walls) of the recorded houses in Mostefa Ben Brahim were constructed with stabilised rammed earth, not the internal partitions. The latter were built using $10-15 \mathrm{~cm}$ thick hollow concrete blocks. Therefore, the implications of the deficiencies in the sample of stabilised rammed earth houses are discussed in relation to their external walls.

External walls of the 30 rammed earth houses in Mostefa Ben Brahim were built by ramming stabilised earth in layers $8-10 \mathrm{~cm}$ thick between integral modular metal shuttering. First of all, small manual metal rammers were used along the shutterings to give a hard and very resistant layer. Crude ramming was then carried out using $12 \mathrm{~kg}$ cast iron rammers

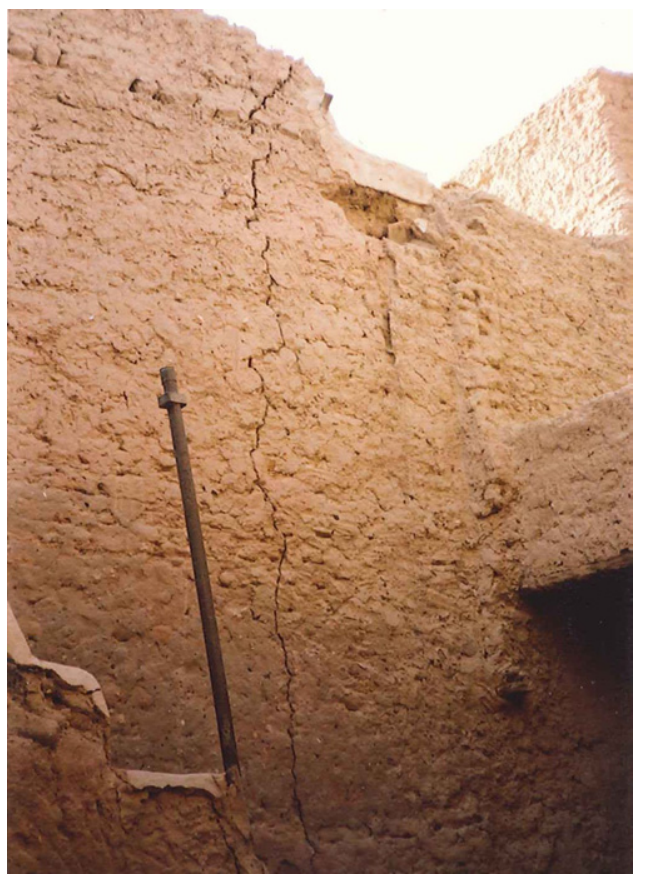

Figure 4. A vertical crack running across the full height of a wall of a vernacular dwelling in Taghit

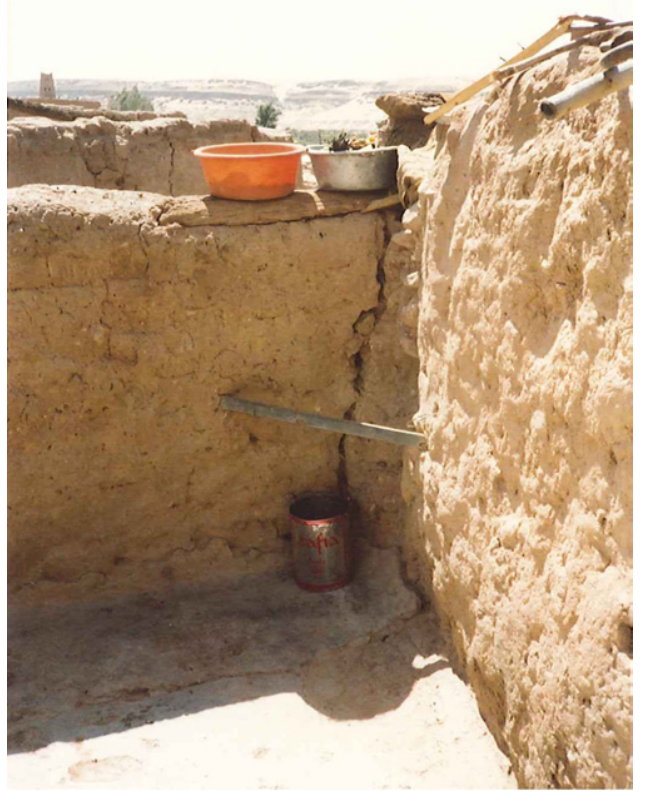

Figure 5. A large crack separating two walls at the corner in one of the vernacular dwellings in Taghit 


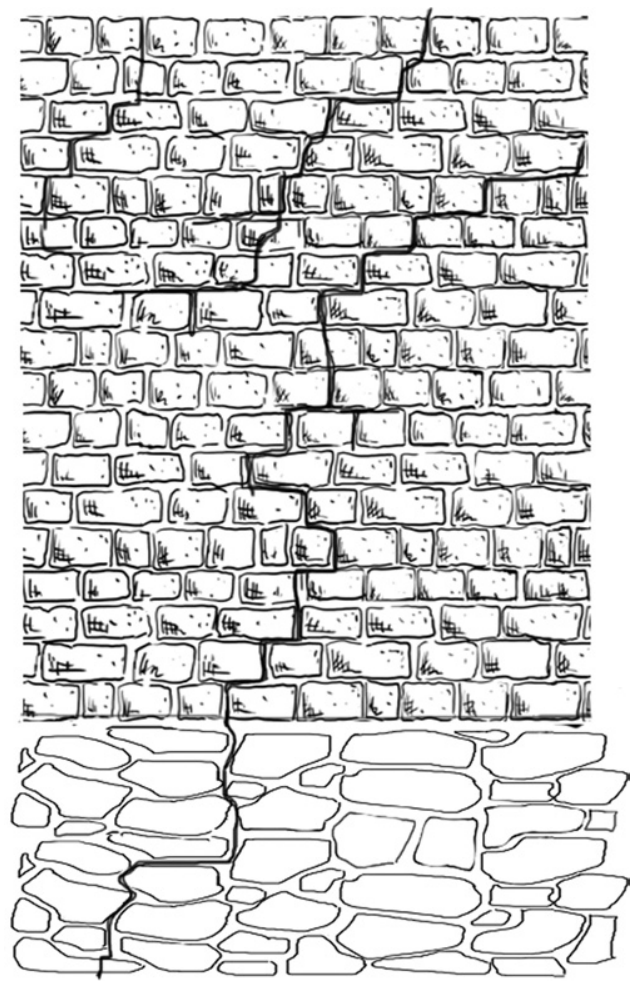

Figure 6. Drawing illustrating the pattern of cracks observed on the walls of the vernacular dwellings in the Ksar of Taghit

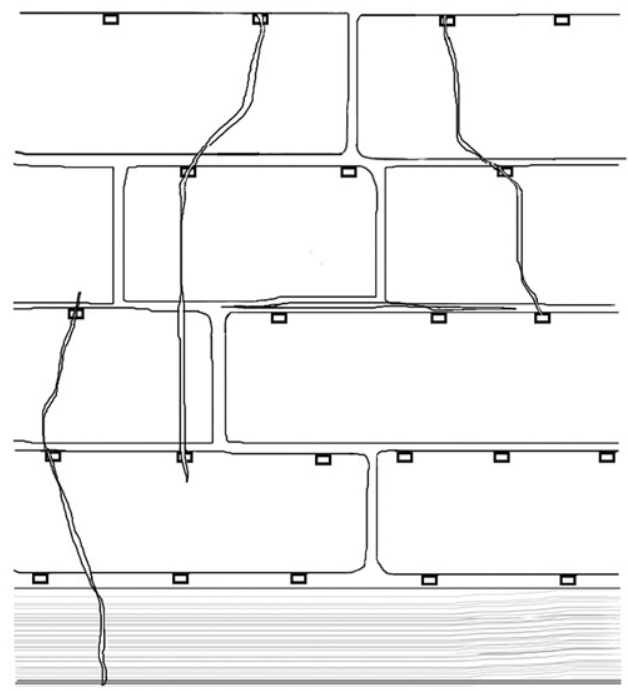

Figure 7. Drawing illustrating the pattern of cracks observed on the walls of the stabilised rammed earth houses in Mostefa Ben Brahim or a RAM 30 Atlas-Copco pneumatic rammer that does the job of ten manual rammers. Thus, the external walls were load bearing, being $40 \mathrm{~cm}$ thick at the ground floor and $30 \mathrm{~cm}$ thick on the upper floor. Difficulties were, however, experienced during the implementation of the external walls, particularly relating to the type of shuttering. These issues included: (a) very heavy damping in the walls; $(b)$ bulging of the shuttering panels due to the high pressures exerted by ramming; (c) heavy shuttering panels (50 kg each); $(d)$ difficulty in fitting the panels together; (e) plumb-line very delicate to maintain; $(f)$ bad finish at the construction joints; $(g)$ the holes made by the cross-pieces supporting the panels caused several problems (removal, filling, cracking etc.) (Pedrotti et al., 1973). It seems that all these observed problems during construction, together with other factors suggested in the literature, may have contributed to the construction and structural problems identified in the external walls of the sample of houses in Mostefa Ben Brahim. These structural and construction deficiencies are mainly illustrated by the repeated patterns of vertical and horizontal cracks. These are discussed in the following sections.

\subsubsection{VERTICAL CRACKS}

When surveying the rammed earth housing in Mostefa Ben Brahim, a pattern of vertical cracks was identified on the external walls of the dwellings. Each external wall appeared to have a number of vertical cracks. Some of these cracks were visible on both inner and outer sides of the walls, implying that these were potentially deep cracks running across the thickness of the walls. Others were visible only on one side of the walls, but this does not mean that these were only superficial cracks (Figures 8 and 9).

The causes of these vertical cracks are not obvious, but there is a high probability that the holes of cross-pieces that supported the shutterings - the weak points in the construction contributed to these cracks. This claim is supported by CRATerre in their report. This is also backed up by anecdotal evidence from a local builder who was working on the site during the implementation of the scheme. He claimed that each time they removed the shutterings and the cross-pieces supporting them, they knocked hard on the cross-pieces to get these out of the wall, which was still wet at this stage. As a consequence, the vibrations might have been transmitted through the wall from its weak points, thus causing these vertical cracks. The sizes of the different particles and lumps in the soil used and its nature might have also contributed to these cracks. In addition, many of these vertical cracks run the full height of the walls and even through the plinth walls, as discussed earlier. A number of possible assumptions of the causes of these cracks can be made - that is foundation failure, including support settlement, heave in clay soils, or any overloading or thermal movement. 


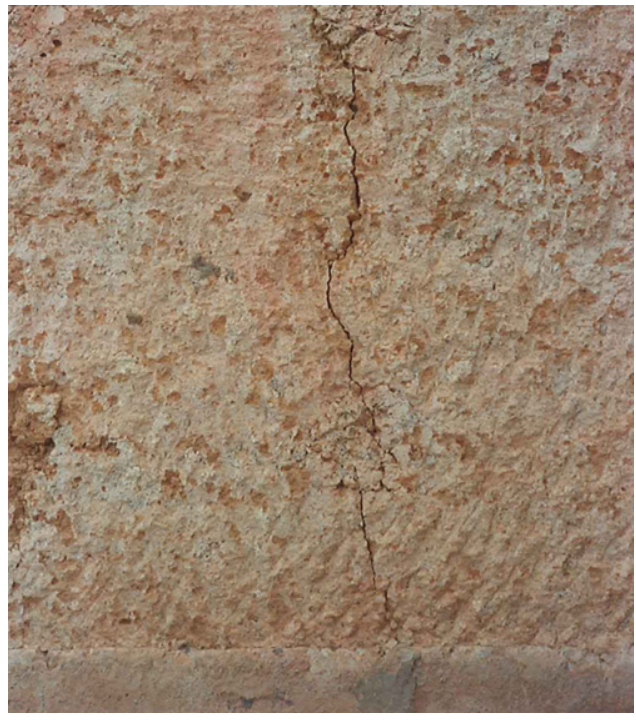

Figure 8. A vertical crack running across the full height of a wall of a rammed earth house in Mostefa Ben Brahim. Note the crack passing through the filled holes of the shuttering cross-pieces

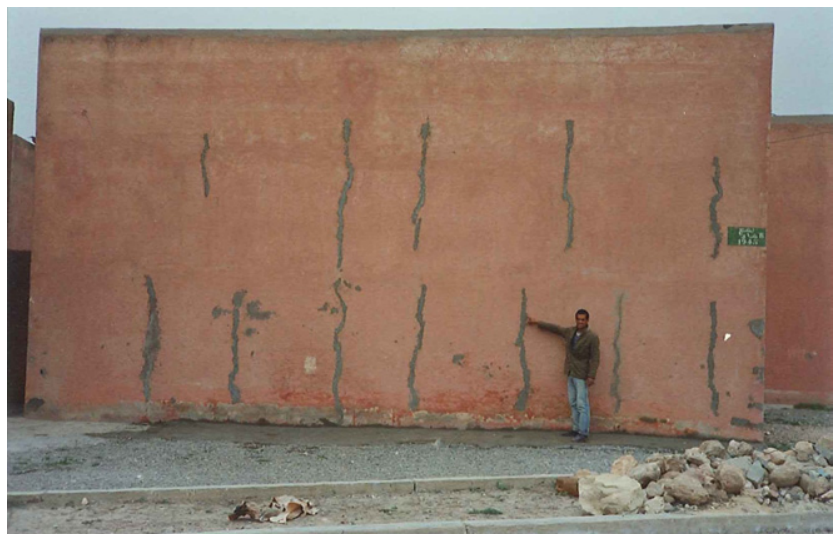

Figure 9. The pattern of vertical cracks identified on the external rammed earth walls of the houses in Mostefa Ben Brahim

\subsubsection{HORIZONTAL CRACKS}

Another pattern of cracks was also observed on the external walls of the stabilised rammed earth dwellings. This second pattern consisted of horizontal cracks located at different levels of the external walls of the recorded houses. Some of these horizontal cracks were visible inside and outside the wall, implying that these were deep cracks running across the thickness of the walls; others were visible only on one side of the wall. However, the depths of these horizontal cracks were not clear (Figure 10).

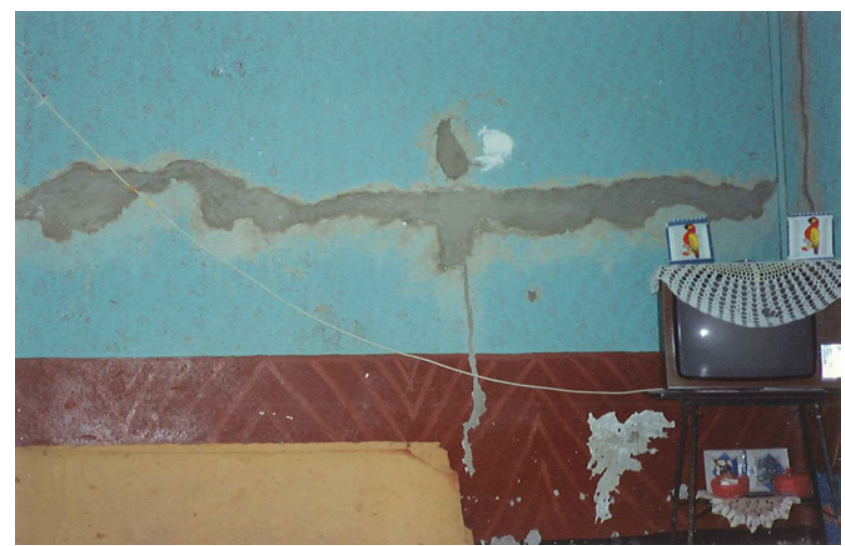

Figure 10. A repaired horizontal crack in the middle of the inside face of the external rammed earth wall in a house in Mostefa Ben Brahim. Note the repaired vertical crack on the right-hand side wall

As the pattern was repetitive, it seems worthwhile discussing the potential causes of these horizontal cracks. First, the appearance of horizontal cracks at the bottom of the wall at the ground floor level or in the external walls as observed from outside might be caused by a bonding failure or a thermal movement between the plinth wall and the stabilised rammed earth wall. This problem was reported by a resident in Mostefa Ben Brahim, who claimed that when it snowed in the past, snow accumulated against the north wall of his living room, which was also the courtyard wall of his neighbour's house; then water infiltrated into his living room through the horizontal crack at the interface between the plinth wall and the rammed earth. Cracks that appeared either at the top or middle parts of walls may have potentially been caused by either horizontal movement and/or a failed bonding between the subsequent rammed earth lifts or layers.

\subsubsection{Wall renders}

Traditionally, similar soil mixture used for making the bricks for the dwellings in the Ksar of Taghit was also used for the mortar, rendering and maintenance, and repair of the dwellings. Due to the arid conditions from the local climate and poor workmanship, shrinkage cracking developed on almost all the renders of the houses recorded in the Ksar. Sometimes the cracks on the rendering were considerable, particularly on the rendering of walls that are open to the elements. In addition, frequent sandstorms caused many walls to be eroded. Erosion was not limited to the rendering; in some cases, it affected the walls.

Rains affected the durability of the wall rendering of the vernacular earth dwellings in the Ksar. During occasional violent 
rain, many walls and their rendering were washed away. This was particularly true in external walls and walls on first floors that tended to be open. In many cases, there was a debonding of the rendering from the wall, probably due to poor workmanship and bad selection of appropriate soil for rendering, which possibly had different resistance to that of the wall.

Little detail is given on CRATerre's report on the render mix used for the rammed earth houses. The report simply stated that the main type of external rendering used to protect the external faces of the load-bearing construction shell consisted of gauge rendering with a roughcast finish consisting of a mixture of sand, cement, lime and $5 \mathrm{~mm}$ graded gravel finish.

Among the 22 houses recorded, only seven appeared to have kept the original external rendering, but this was not in a good state of repair; 15 houses had different types of external rendering, including cement-based rendering. This suggests that there were problems with the original type of external rendering.

The main problems observed consisted of bulging, cracking and patches where rendering was missing altogether. The external rendering of all of the recorded houses in Mostefa Ben Brahim, especially those still coated externally with roughcast, showed vulnerability of such type of cladding (Figure 11). The areas where rendering was either missing or cracked could be observed with the naked eye. However, bulging (suggesting rendering/wall debonding) was detected by knocking gently on the rendering with a clenched fist. These types of problems were not restricted to roughcast finish, but were also visible on the external rendering of houses with other types of rendering. The external rendering of many of these houses exhibited

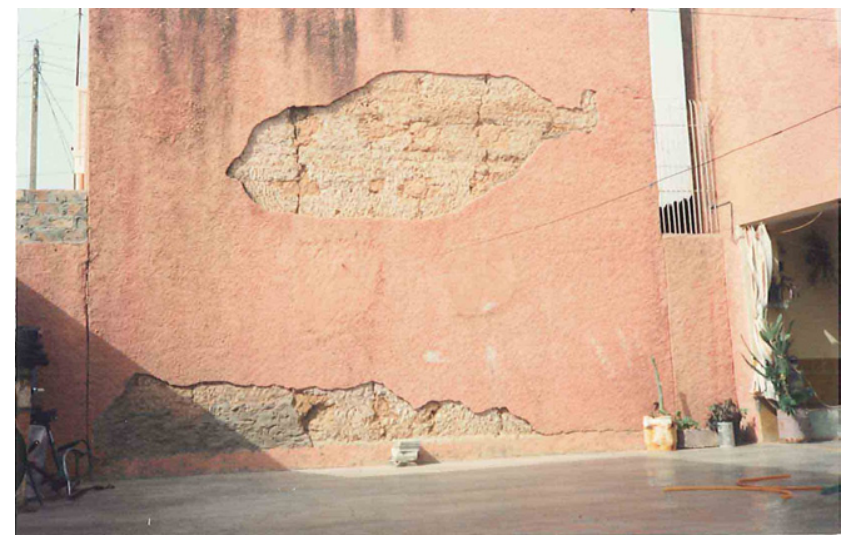

Figure 11. Vulnerability of the roughcast rendering used for the rammed earth houses in Mostefa Ben Brahim. Note the vertical cracks on the wall and black patches at the top of the wall hairline cracks and some small patches of missing rendering. In one case, it was noticed that the whole external rendering had been re-done completely using cement-based mortar, which suggested failure of the original roughcast rendering.

Failure of the external rendering of the stabilised rammed earth houses in Mostefa Ben Brahim was in several cases exacerbated by the inefficient rainwater evacuation system. The inefficiency of the rainwater pipe system was attributed to the pipe material, diameter, number and location of the pipe. One downpipe was provided for the evacuation of rainwater from the roofs of the houses. The pipe, whose diameter was between 10 and $12 \mathrm{~cm}$, was made of polyvinyl chloride (PVC) and fixed to the middle of the eave gutter on the south facade. It was claimed that, due to its narrow diameter, the pipe sometimes became blocked by dirt, dust or dead animals such as pigeons.

When the only downpipe was blocked, the eave gutter filled with water and would then overflow at the ends and in the middle. The effect of this problem is clearly visible at the top of south facades of the majority of houses, such as spalling and flaking of rendering (Figure 12).

Poor workmanship too contributed to the problem. CRATerre, in their early report on this housing scheme, admitted that the walls should have been completely scratched or chipped before the render was applied. In this respect, for them a rough shuttering could have been more appropriate in order to get a rough surface, allowing a good bond between the rammed earth wall and the render. The report also claimed that even the gauge or lime plaster was disconnecting from the walls. It was also reported that there had been difficulties preparing and applying earth-based plasters, as in this case at least two

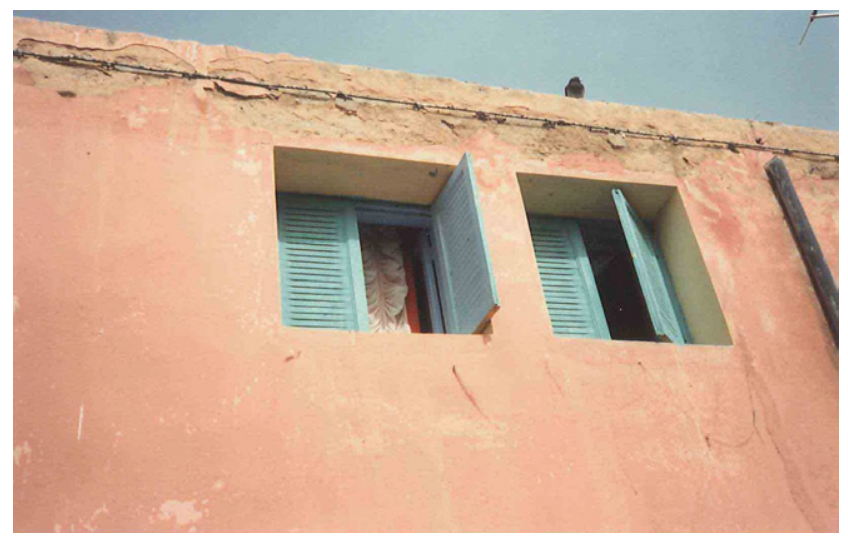

Figure 12. Vulnerability of rendering at the top of an external wall of a rammed earth house in Mostefa Ben Brahim, showing spalling of the rendering 
colour washes a year would be required in order to ensure proper maintenance (Pedrotti et al., 1973).

\subsubsection{Door and window openings}

In Taghit, the door and window lintels of the vernacular earth dwellings usually consisted of two to four palm trunk sections laid adjacent to each other. In a few cases, planks of other types of timber were used in combination with the palm trunk sections. Many of these timber lintels sagged under the heavy weight of the earth structure.

In Mostefa Ben Brahim, the door and window openings of the stabilised rammed earth houses were not simply spanned by lintels, but were reinforced with frames made of precast, reinforced concrete pieces, to provide extra strength to the weak openings. It was claimed that such precast pieces required meticulous fitting when these were put in place.

An empirical observation was made on the windows from both outside and inside to assess how deep these arched cracks were on the stabilised rammed earth wall. The depth of several of the cracks was obvious, as these could be traced in the same location on the outside face and the inside face of the same wall. This means that these cracks went across the whole thickness of the wall. In other cases, it was difficult to estimate the depth of the cracks with the naked eye. Some windows had one or two visible arched cracks at their bottom corners, whereas others did not exhibit any crack at all; however, this did not mean that the cracks did not exist.

A very thorough technical investigation would be required to determine the scale and cause of these types of cracks. Nevertheless, according to Jeannet et al. (1986), this type of crack occurs in many rammed earth buildings because during the ramming and compaction, the walls crack at the most vulnerable places, generally where there is the least material. In the case of large openings, lintels and arches might bend, particularly if these are not anchored properly; cracks that occur as a result of this take the shape of a discharging arch marking the limits of the tension and compression zones. These types of arched cracks are usually the result of a punching effect by the window sills and are called 'moustaches' (Jeannet et al., 1986) (Figure 13).

\section{Conclusions and recommendations}

The main conclusions are as follows.

(a) Despite the new houses in the second case study being built with improved earth-based materials, these displayed deficiencies in strength and durability, some of which were similar to those exhibited in the old earth dwellings. This was the case even though meticulous

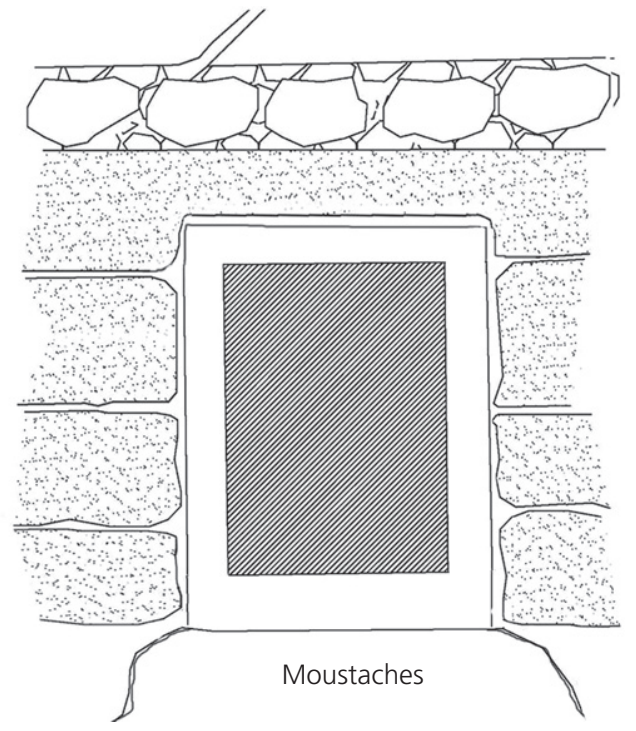

Figure 13. 'Moustache' cracks observed the bottom corners of window openings of the rammed earth houses in Mostefa Ben Brahim

laboratory research was conducted to improve the quality of soil prior to construction, not only by Algerian bodies involved in earth construction technology, but also by foreign organisations working in/cooperating with such bodies. In effect, the strength and durability of the earth samples established on the basis of laboratory tests were not achieved in the completed buildings that were in use.

(b) This leads to the conclusion that the building techniques and/or the workmanship were not sufficiently able to exploit the established strength qualities of the earth material.

(c) The use of other materials in combination with earth construction has to be carefully reviewed in terms of strength, compatibility and design. In particular, in relation to the second case study, sagging beams, differential movement of rendering, and difficulty in consistent compaction around wooden windows and doors surrounds caused failures in the structural integrity of the walls.

These findings indicate that although earth may be locally available and tested as suitable for using in construction, problems could be encountered due to the design process, the construction system, the use of components with other material properties, workmanship, and the maintenance and repair activities. These factors either separately or in combination can significantly influence the structural integrity of the buildings.

The recommendation is that for each proposed project a careful assessment should be made before building begins - of 
the suitability of the local earth, the appropriateness of the design and construction technique, the availability of suitably trained builders, and the involvement of the users in the process of building and subsequent maintenance and repair of the completed dwellings.

Despite all the issues mentioned above, earth construction can go a long way towards the provision of housing in the rural areas of many developing countries, including Algeria, where suitable earth is available, provided there is a sound examination and understanding of the soil properties. This is strongly encouraged by the technological development that has emanated from the enormous body of research that has been carried out in this field.

\section{Acknowledgements}

The authors acknowledge the support of the local authorities and all the residents of both Taghit (West of Bechar) and Mostefa Ben Brahim (West of Sidi Bel-Abbes) for their help and assistance during the field work. In addition, the authors thank Mr Shahaboddin Resalati and Mrs Shahrzad Amouzad for helping with graphics.

\section{REFERENCES}

Adam EA and Agib ARA (2001) Compressed Stabilised Earth Block Manufacture in Sudan. Unesco, Paris, France. Agarwal A (1981) Mud, Mud. The Potential of Earth-Based Materials for Third World Housing. Earthscan, London, UK.

Agarwal A (1982) Research: mud as a traditional building material. The Changing Rural Habitat I: 137-146. (Case Studies, The Aga Khan Awards)

Angulo-lbáñez Q, Mas-Tomás Á, Galvañ-LLopis V and Sántolaria-Montesinos JL (2012) Traditional braces of earth constructions. Construction and Building Materials 30: 389-399.

Arrecchi A (1984) Rural settlement experience in Postcolonial Africa. Ekistics 304: 47-56.

BADC (The Information Service of the Belgian Administration for Development Co-operation) (1985) Building with earth. Dimension 3 (4). (Special Issue).

Baiche B (1987) The Potential for Innovation in Contemporary Rural House Building in Algeria. MPhil thesis, Oxford Polytechnic, Oxford, UK.

Baiche B (1992) Contemporary Rural Housing Built with Improved Earth-Based Materials in Algeria. PhD thesis, Oxford Brookes University, Oxford, UK.

Beazley E and Haverson M (1982) Living with the Desert: Working Building of the Iranian Plateau. Aris and Phillips Ltd, Warminster, UK.

Chel A and Tiwar GN (2009) Thermal performance and embodied energy analysis of a passive house - case study of vault roof mud-house in India. Applied Energy 86(10): 1956-1969.

Ciancio D and Boulter M (2012) Stabilised rammed earth: a case study in western Australia. Proceedings of the Institution of Civil Engineer - Engineering Sustainability 165(2): 141-154, http://dx.doi.org/10.1680/ensu.10.00003 U2-10.1680/ensu.

CIB (International Council for Building Research, Studies and Documentation) and Rilem (The International Union of Laboratories and Experts in Construction Materials, Systems and Structures) (1983) Appropriate Building Materials for Low Cost Housing. E. and F.N. Spon Ltd, London, UK, vols 1 and 2.

CIDRLD (Construction Industries Division of the Regulation and Licensing Department) (2004) Mexico Earthen Building Materials Code. New Mexico, USA, vol. XV, p. 21.

Clough WE (1947) Building in Cob, Pisé and Stabilised Earth Country Life Ltd, London, UK.

Courtney C (1986) Hassan Fathy and Philip Johnson, talk to these two octogenarians about each other's work. The Architect pp. 26-28.

CRATerre (1985) Construire en Terre. Editions Alternatives et Paralleles, Paris, France (in French).

CRATerre (2005) Earth Architecture in Uganda: Pilot Project in Bushennyi 2002-2004. CRATerre-EAG Publications, Grenoble, France, p. 34.

Doat P, Hays A, Houben H, Matuk S and Vitoux FN (1979) Construire en Terre. Editions Alternatives, Paris, France (in French).

Duly C (1979) The Houses of Mankind. Thames and Hudson Ltd, London, UK.

Eaton R (1981) Mud: An Examination of Earth Architecture. The Architecture Review 170(1016): pp. 226-230.

Eaton R (Dethier J) (1982) Mud Architecture: An Old Idea, a New Future: Down to Earth. Thames and Hudson Ltd, London, UK.

Emmot D (1981) A Mud Revival. Development Forum (87), United Nations, USA.

Evans M (1980) Housing, Climate and Comfort. The Architectural Press Ltd, London, UK.

Fathy H (1970) Construire avec le Peuple. Edition Sindbad, Paris, France (in French).

Fathy H (1973) Architecture for the Poor. The University of Chicago Press, Chicago, IL, USA.

Fathy H (1986) Natural Energy and Vernacular Architecture, Principles and Examples with Reference Hot Arid Climates. The University of Chicago Press, Chicago, IL, USA.

Ferm R (1985) Stabilised Earth Construction: An Instructional Manual. The International Foundation for Earth Construction, Washington, DC, USA.

Fodde E (2009) Traditional earthen building techniques in central Asia. International Journal of Architectural Heritage 3(2): $145-168$ 
Germen A (1979) The endurance of earth as a building material - and the discreet but continuous charm of adobe. METU Journal of the Faculty of Architecture 5(1): 37-53.

Guillaud H (1985) Au Debut Etait la Terre un Materiau aux Usages Multiples. La revue ' $H$ ', Publiée par l'Union Nationale des H.L.M à Paris (111): 39-44 (in French).

Hadjri K (2005) Experimenting with hybrid construction Guadua bamboo and adobe - for housing in rural Colombia. International Journal for Housing Science and its Application 29(2): 165-177.

Hadjri K, Osmani M, Baiche B and Chifunda C (2007) Attitudes towards earth building for Zambian housing provision. Proceedings of the Institution of Civil Engineers Engineering Sustainability 160(3): 141-150, http://dx.doi. org/10.1680/ensu.2007.160.3.141.

Hall M, Lindsay R and Krayenhoff M (2012) Modern Earth Buildings: Materials, Engineering, Constructions and Applications. Woodhead Publishing, Cambridge, UK

Houben H and Guillaud H (1994) Earth Construction. A Comprehensive Guide. Intermediate Technology Publications, London, UK.

Houben H, Rigassi V and Garnier P (1996) Compressed Earth Blocks: Production Equipment. CRATerre-EAG, Grenoble, France.

Hyland ADC (1984) The Arab House. Report of a Colloquium Held at the School of Architecture. University of NewcastleUpon-Tyne, UK, 15-16 March. Third World Planning Review, November, pp. 389-394.

Jayasinghe C and Kamaladasa N (2007) Compressive strength characteristics of cement stabilized rammed earth walls. Construction and Building Materials 21(11): 1971-1976.

Jeannet J, Pollet $\mathrm{G}$ and Scarato $\mathrm{P}$ (of the 'Pisé Association) (1986) Le Pisé - Patrimoine - Restauration - Technique d'Avenir. Editions CREER, Nonette, France (in French).

Jenner M (1984) Mud-brick-building in Yemen. UR, The International Magazine of Arab Culture (2): 2-5.

Jiménez Delgado MC and Ignacio Cañas Guerrero I (2006) Earth building in Spain. Construction and Building Materials 20(9): 679-690.

Kateregga JK (1983) Improvement and Use of Earth Construction Products for Low Cost Housing. Appropriate Building Materials for Low Cost Housing. CIB and RILEM, E. and F.N. Spon, London, UK, pp. 23-33.

Keable J (1996) Rammed Earth Structures. A Code of Practice. Intermediate Technology Publications, London, UK.

Keefe L (2005) Earth Building: Methods and Materials, Repair and Conservation. Taylor and Francis, London, UK.

Kuban D (1982) Some remarks on environmental appreciation. The Changing Rural Habitat I: 147-148. (Case Studies, The Aga Khan Awards).

McHenry PG Jr (1984) Adobe and Rammed Earth Buildings, Design and Construction. John Wiley and Sons, New York, NY, USA.
McHenry P (1989) Adobe and Rammed Earth Building: Design and Construction. The University of Arizona Press, Tucson, Arizona, USA.

Millogo Y, Hajjaji M and Ouedraogo R (2008) Microstructure and physical properties of lime-clayey adobe bricks. Construction and Building Materials 22(12): 2386-2392.

Minke G (2000) Earth Construction Handbook: The Building Material Earth in Modern Architecture. WIT Press, Southampton, UK.

Montgomery DE (2002) Dynamically-Compacted Cement Stabilized Soil Blocks for Low-Cost Walling. PhD thesis, School of Engineering, University of Warwick, Warwick, UK.

Tom M, Fionn S, Taylor B and Charlton Smith N (2005) Low Cost Earth Brick Construction. Arc, Chartered Architects, Fife, UK.

Mulligan H (1987) Back to the land. Building Design (822): $14-15$.

Ngowi AB (1997) Improving the traditional earth construction: a case study of Botswana. Construction and Building Materials 11(7): 1-7.

Norton J (1997) Building with Earth - A Handbook, 2nd edn. Intermediate Technology Publications, UK.

Nowamooz H and Chazallon C (2011) Finite element modelling of a rammed earth wall. Construction and Building Materials 25(4): 2112-2121.

Nyerere JK (1977) The Arusha Declaration: Ten Years After. Tanzania Publishing House, Dar Es Salaam, Tanzania.

Olotuah AO (2002) Recourse to earth for low-cost housing in Nigeria. Building and Environment 37(1): 123-129.

Pacheco-Torgal F and Jalali S (2012) Earth construction: lessons from the past for future eco-efficient construction. Construction and Building Materials 29: 512-519.

Parra-Saldivar ML and Batty W (2006) Thermal behaviour of adobe constructions. Building and Environment 41(12): 1892-1904.

Pedrotti P, Belmans D and Houben H (1973) L'Experience $d u$ Village Agricole de Mostefa Ben Brahim-30 Maisons en Pisé - Algerie (in French).

Prin D and Cubaid JC (1983) (du Centre de Recherches sur l'Habitat, Institut national des Sciences Appliquées de Lyon) La Stabilisation des Terres et les Mecanismes Physico-chimiques liés a la Cristallisation a Froid. Construire, Revue du secteur de la construction (2): 41-49 (in French).

Schleifer AS (1984) Hassan Fathy's Abiquiu: an experimental islamic educational center in rural New Mexico. Ekistics 304: $56-60$.

Schumacher EF (1973) Small is Beautiful: Economics as if People Mattered. Harper, New York, NY, USA.

Shukla A, Tiwari GN and Sodha MS (2009) Embodied energy analysis of adobe house. Renewable Energy 34(3): $755-761$. 
Spence RJS and Cook DJ (1983) Building Materials in Developing Countries. John Wiley and Sons Ltd, London, UK.

Staveley HS and Glover PV (1983) Surveying Buildings. Butterworths, London, UK, pp. 15-25.

Swan S (1980) Hassan Fathy demonstrates ancient construction methods in New Mexico. Architectural Record 36.

Swenarton M (2003) Rammed earth revival: technological innovation and government policy in Britain, 1905-1925.
Construction History: Journal of the Construction History Group V, 19: 107-126.

Venkatarama Reddy BV and Jagadish KS (2003) Embodied energy of common and alternative building materials and technologies. Energy and Buildings 35(2): 129-137.

Walker P (2005) Rammed Earth: Design and Construction Guidelines. BRE Bookshop, Watford, UK.

Yorulmaz M (1982) Earthquakes and rural construction. The Changing Rural Habitat I: 131-134. (Case Studies, The Aga Khan Awards).

\section{WHAT DO YOU THINK?}

To discuss this paper, please email up to 500 words to the editor at journals@ice.org.uk. Your contribution will be forwarded to the author(s) for a reply and, if considered appropriate by the editorial panel, will be published as discussion in a future issue of the journal.

Proceedings journals rely entirely on contributions sent in by civil engineering professionals, academics and students. Papers should be 2000-5000 words long (briefing papers should be 1000-2000 words long), with adequate illustrations and references. You can submit your paper online via www.icevirtuallibrary.com/content/journals, where you will also find detailed author guidelines. 